\title{
Congenital corneal anaesthesia and the MURCS association: a case report
}

\author{
L ESAKOWITZ' AND J R W YATES
}

From the 'Tennent Institute of Ophthalmology, Western Infirmary, Glasgow G11 6NT, and the

${ }^{2}$ Duncan Guthrie Institute of Medical Genetics, Yorkhill, Glasgow G3 8SJ

SUMMARY Bilateral corneal anaesthesia and reduced sensation in the distribution of the ophthalmic division of the fifth cranial nerve associated with neuroparalytic keratitis and reduced vision is described in a 26-year-old woman with absence of the fallopian tubes, uterus, and upper vagina, a single pelvic kidney, and cervico-thoracic vertebral anomalies (the MURCS association). Other features of the disorder also present were short stature, facial asymmetry, micrognathia, and cleft palate. The neuroparalytic keratitis did not respond to tear substitutes and bilateral lateral tarsorrhaphies were eventually needed. This is the first report of congenital corneal anaesthesia in a case of MURCS.

Congenital corneal anaesthesia ${ }^{12}$ is a rare condition that occurs in isolation but has also been described in the Goldenhar syndrome, ${ }^{3}$ the Riley-Day syndrome, ${ }^{4}$ and in congenital universal insensitivity to pain. ${ }^{5}$ We now report bilateral congenital corneal anaesthesia in a patient with the MURCS association (for elucidation of this acronym see 'Discussion' below).

\section{Case report}

A 29-year-old woman presented to the Department of Ophthalmology with a one-year history of red eyes and reduced vision without pain. She gave a history of a left corneal ulcer at the age of 18 years which had caused mild photophobia but no other discomfort.

The patient had been born with a cleft palate, which was repaired at 18 months of age. At 19 years she was investigated for primary amenorrhoea and was noted to have a short webbed neck and unusual facies. There was a systolic murmur at the cardiac apex. She had normal female external genitalia, but the vagina was a blind ending pouch only $3 \mathrm{~cm}$ deep. Laparoscopy revealed complete absence of the uterus and fallopian tubes. Both ovaries were present and normal in appearance. Gonadotrophins and sex steroid levels were in the adult female range. A buccal smear was sex chromatin-positive, and chromosome analysis gave a normal female karyo-

Correspondence to L Esakowitz, Department of Ophthalmology, Aberdeen Royal Infirmary, Foresterhill, Aberdeen AB9 2ZD. type. Chest $x$-ray, electrocardiogram, and echocardiograph were normal. An intravenous pyelogram showed a normally shaped and functioning right kidney located in the pelvis. No left kidney was demonstrated. The patient had a vaginoplasty carried out at 26 years of age.

Her parents were healthy and unrelated. A brother had died at birth from a narrow airway, possibly laryngeal or tracheal stenosis. Another brother and a sister were alive and well, and there was no relevant family history.

Her best corrected visual acuity was $6 / 12$ right and $6 / 24$ left. The conjunctivae of both eyes were moderately and diffusely injected. There was diffuse punctate epithelial opacification of both corneas, more marked in the interpalpebral areas, and some of the punctate opacities stained with fluorescein and rose Bengal. A superficial stromal and epithelial scar was present temporally on the left cornea (Fig. 1). Corneal and conjunctival sensation were reduced bilaterally; a reaction was noted on stimulation with $5 \mathrm{~mm}$ of nylon fibre using the corneal aesthesiometer of Cochet and Bonnet. ${ }^{6}$ Pinprick stimuli were perceived as dull in the skin distribution of the ophthalmic division of the trigeminal nerve bilaterally. No stinging sensation was noted on instillation of benoxinate drops, and applanation tonometry was performed without the need for topical anaesthesia. An unstimulated Schirmer's test revealed $3 \mathrm{~mm}$ of wetting of the paper in 5 minutes bilaterally; however, 


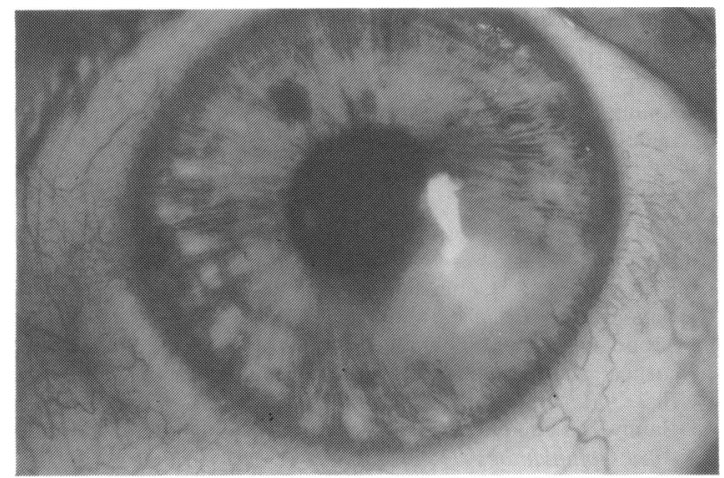

Fig. 1 Left cornea, showing the epithelial and stromal scar.

there appeared to be an adequate lacrimal lake. Corneal nerves were seen to be present and appeared normal in size and distribution. Brushfield's spots were noted on both irides. The corneoscleral angles, lens, retina, and optic disc all appeared normal.

General examination showed a standing height of $153.7 \mathrm{~cm}$ (just below the 10th centile), sitting height of $80 \mathrm{~cm}(2.5$ standard deviations below the mean $)$, subischial height $73.7 \mathrm{~cm}$ (close to the mean), and span $158 \mathrm{~cm}$. Her head circumference was $56 \mathrm{~cm}$ (one standard deviation above the mean). She had a prominent and asymmetrically placed nose, malar hypoplasia, micrognathia and marked deviation of the jaw to the left on opening (Fig. 2). The ears were low set. Her neck was short, with webbing and a low posterior hair line. She had a normal female habitus with fully developed secondary sexual characteristics. Her intelligence was normal.

Chromosome analysis again showed a normal female karyotype. Radiographs of the spine showed

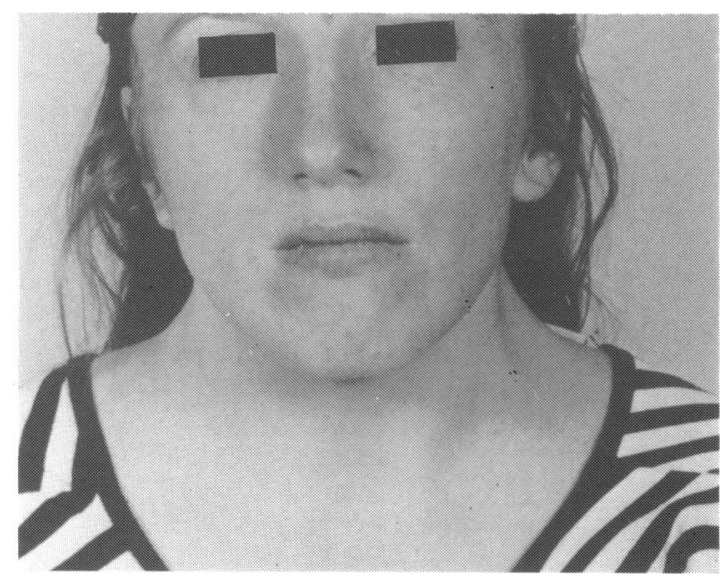

Fig. 2 Malar hypoplasia, micrognathia, asymmetric nose, and webbed neck. scoliosis with congenital fusion of the cervical vertebrae, C3 with $\mathrm{C} 4$ and $\mathrm{C} 5$ with $\mathrm{C} 6$. The 5th thoracic vertebra was a butterfly vertebra (hypoplasia of the vertebral body), and there was an accessory lumbar vertebra. Ultrasound examination confirmed absence of the left kidney and uterus. The right kidney was seen lying at the level of the pelvic brim. There was mild conductive deafness in her left ear with slight scarring of the tympanic membrane. Her right ear was normal.

Frequent instillations of tear substitutes were of some help, but bilateral partial tarsorrhaphies were eventually required to improve the keratitis.

\section{Discussion}

The acronym MURCS stands for (MÜ)llarian duct aplasia, (R)enal aplasia, and (C)ervical (S)omite dysplasia, the characteristic findings being absence of the uterus and vagina with normal external genitalia, renal ectopy and/or agenesis, cervicothoracic vertebral defects, and short stature. ${ }^{7}$ The ovaries are normal, and secondary sexual development occurs at puberty. The vertebral defects such as fused or hemivertebrae particularly involve C5-D1. The term Klippel-Feil anomaly is used in severe cases with extensive fusion of cervical vertebrae resulting in a short neck and restricted movement. ${ }^{8}$ Other features of MURCS shown by our patient are facial asymmetry, micrognathia, and cleft palate. MURCS appears to be a sporadic disorder and familial recurrence has not been reported.

Congenital corneal anaesthesia has not previously been reported in the MURCS association. Cases of congenital corneal anaesthesia typically present with painless corneal ulcers and signs of neuroparalytic keratitis, ' as did our patient. Lack of pain with severe corneal and conjunctival irritation and the history of a painless corneal ulcer in one eye alerted us to the presence of anaesthesia. It is important to exclude secondary causes of corneal anaesthesia before the diagnosis of congenital corneal anaesthesia can be considered. ${ }^{9}$ Trigeminal nerve impairment can result from space occupying lesions of the cerebellopontine angle or diseases of the coronal sinus. Orbital apex lesions such as tumours or pseudotumours usually involve the ophthalmic nerve. Ocular causes of acquired corneal anaesthesia include keratitis due to herpes zoster or herpes simplex virus. There was no evidence of a secondary cause for the corneal anaesthesia in our patient.

MURCS has features in common with several other disorders including the VATER association, Wildervanck syndrome, and Goldenhar syndrome. ${ }^{10}$ The VATER association consists of (V)ertebral defects, (A)nal atresia, (T)racheo-(E)sophageal 
fistula with oesophageal atresia, (R)adial (skeletal), and (R)enal defects." To our knowledge no ocular anomalies have been described in this condition. Wildervanck syndrome has cervical vertebral and auditory anomalies in common with MURCS. It consists of Duane's syndrome, Klippel-Feil anomaly, crocodile tears (anomalous lacrimal innervation), and deafness. ${ }^{1213}$ No cases with congenital corneal anaesthesia have been described.

Congenital corneal anaesthesia has been reported in several patients with Goldenhar syndrome,${ }^{3}$ which consists of a symmetrical or unilateral hypoplasia of the facial bones, preauricular tags or fistulae, microtia, cervical vertebral anomalies, and epibulbar dermoids. Asymmetric astigmatism has been noted in some eyes with epibulbar dermoids. Renal anomalies have occasionally been reported. The cause is unknown and most cases have been sporadic.

The cause of the anomalies in the MURCS association has yet to be established. During the fourth embryonic week there is a stage when the pronephros and cervical somites are in close proximity, and a disturbance at this time could produce the spectrum of defects seen. ${ }^{7}$ Congenital corneal anaesthesia represents an isolated defect of the ophthalmic branch of the fifth cranial nerve and may also result from a disturbance in early embryogenesis. The maxillary and mandibular divisions of the trigeminal nerve ganglion develop from neural crest cells associated with the first branchial arch, but the ophthalmic nerve ganglion cells are non-branchial and initially develop separately, only later fusing with the other components of the ganglion. ${ }^{14}$

It is important that ophthalmologists examining patients with cervical vertebral anomalies and a corneal disturbance are aware of the possibility of congenital corneal anaesthesia, because the associ- ated neuroparalytic keratitis will require special management.

We thank Dr J S C Cant for allowing us to report his patient, and $\mathrm{Mr}$ J Muldoon for providing details of past investigations, Mrs A Curric for her photographic assistance, and Mrs L McKain for typing the manuscript.

\section{References}

1 Rosenburg ML. Congenital corneal anaesthesia, a review and classification. Brain 1984; 107: 1073-82.

2 Trope GE, Jay JL, Dudgeon J, Woodruff G. Self-inflicted corneal injuries in children with congenital corneal anaesthesia. Br J Ophthalmol 1985; 69: 551-4.

3 Baum JL, Feingold M. Ocular aspects of Goldenhar's syndrome. Am J Ophthalmol 1973; 75 : 250-7

4 Goldberg MF, Payne JWT, Brunt PW. Ophthalmological studies of familial dysauonomia (the Riley-Day syndrome). Arch Ophthalmol 1968; 80: 732-43.

5 Ford FK, Wilkens L. Congenital universal insensitivity to pain. Bull Johns Hopk Hosp 1938; 62: 448-65.

6 Miller NR. Walsh and Hoyt's clinical neuro-ophthalmology. 4th ed. Baltimore: Williams and Wilkins, 1985; 2: 1044-5.

7 Duncan PA, Shapiro LR, Stangel JJ, Klein RM, Addonizio JC. The MURCS association: müllerian duct aplasia, renal aplasia and cervical somite dysplasia. J Pediatr 1979; 95: 399-402.

8 Gunderson $\mathrm{CH}$. The Klippel-Feil syndrome: genetic and clinical re-evaluation of cervical fusion. Medicine 1967; 46: 491-509.

9 Grayson M. Diseases of the cornea. 2nd ed. St Louis: Mosby, 1983: 529-30.

10 Russell LJ, Weaver DD, Bull MJ. Axial mesodermal dysplasia spectrum. Pediatrics 1981; 67: 176-82.

11 Temtamy SA, Miller JD. Extending the scope of the VATER association: definition of a VATER syndrome. J Pediatr 1974; 85: 345-9.

12 Cremers CWRJ, Hoogland GA, Kuypers W. Hearing loss in the cervico-oculo-acoustic (Wildervanck) syndrome. Arch Otolaryngol 1984; 110: 54-7.

13 Ramsey J, Taylor D. Congenital crocodile tears: a key to the aetiology of Duane's syndrome. Br J Ophthalmol 1980; 64: 518-22.

14 Hamilton WJ. Hamilton, Boyd and Mossman's Human Embryology, Pre-Natal Development of Form and Function. 4th ed. Cambridge: Heffer, 1972: 493.

Accepted for publication 29 January 1987. 